\title{
Montefiore Demonstration Project
}

\section{Practical Nurse Training in the Home}

\author{
By MARTIN CHERKASKY, M.D., ELIZABETH B. TORRANCE, M.A., R.N., \\ ELSIE BANDMAN, M.A., R.N., and BETTY SEIFMAN, M.A., R.N.
}

$\mathrm{T}$ HE INCREASE in chronic disease has created a host of problems. These derive not only from the mounting number of chronically ill patients, but also from the long duration of chronic disease and the associated emotional, social, and economic disorders that affect both patient and family.

The changing character of illness is shown by reports from visiting nurse agencies throughout the country that their services are devoted more and more to patients with chronic disease. The Visiting Nurse Service of New York reported that in a recent 6 -month period 70 percent of the visits were to patients with longterm illness.

Because chronic illness is measured in months and even years, it has become neither desirable nor possible for all the chronically ill to be cared for in hospitals, certainly not for the major period of illness. This consideration has caused many changes in the patterns of medical care (1).

Montefiore Hospital, New York City, recognizing the impossibility of providing institutional facilities for all the chronically ill and the undesirability of keeping many patients in

Dr. Cherkasky is director, and Miss Torrance is nursing executive, of Montefiore Hospital in New York City. Miss Bandman, formerly supervisor of the hospital's demonstration project for practical nurse training in the home, is now assistant nursing executive of the hospital's School of Practical Nursing. Miss Seifman succeeded Miss Bandman as supervisor of the demonstration project. institutions rather than in the home with their families, embarked in 1947 upon its home care program. Techniques of providing comprehensive care to patients in the home were fully explored and have in many instances served as the pattern for home care programs throughout the country as well as abroad (2). Of particular significance throughout the United States is a growing number of organized programs of home care designed to meet the complex needs of chronically ill patients within the framework of the home $(3-9)$.

It is fortunate that this necessity has considerable virtue. Montefiore has demonstrated that, for properly selected patients, home care is a method of choice when the basic team of the physician, nurse, and social worker is available to meet the multiple needs of the patient and his family. Of these three, none is more important in this service than the nurse.

The rise in chronic disease, which will assuredly continue, has led not only to a shortage of institutional facilities but to an even more serious shortage, that of nursing personnel. The American Nurses Association reported that there were 389,600 active professional workers at the end of 1953. Of these 231,000 were professional nurses employed in the field of hospital and institutional nursing. An additional 54,123 practical nurses were also employed in that field (10).

Although this was the largest number of professional nurses who had ever practiced in the country, the demand has kept well ahead of the supply. One of the reasons for this demand is the enormous growth of hospital facilities. In 1934 the total number of hospital beds in this 
country, excluding those for the mentally sick and tuberculous, was 464,193, and in 1953 it was 735,215 (11).

In 1940, hospitals pressed by the growing demand of the armed forces for nursing personnel further developed a new hospital worker-the trained practical nurse. Today, patient care would be impossible in many of our hospitals were it not for the trained practical nurse, at first accepted only grudgingly by her colleagues and others in the health field. Her period of training, in contrast to the minimum 3 years for the professional registered nurse, is approximately 1 year. To qualify for practical nurse training at Montefiore Hospital, the student must have certain qualifications:

Age: 17-50.

Education: Elementary school diploma or its equivalent.

Health: Applicant must have good physical and mental health and moral character. Medical and dental records must be filled out by the applicant's own physician and dentist on a form provided by the school.

Selection: An admissions committee makes the final selection, based upon an evaluation of the applicant by personal interview, preentrance testing, and references.

Obviously the pretraining qualifications and the length and extent of training preclude the average practical nurse from assuming the same range of responsibility as the professional nurse. There is, however, no question that, with proper selection of students and a year of carefully planned and supervised training, the practical nurse is prepared for a wide range of nursing services which supplement and complement the services of the professional nurse.

In view of the great problem of chronic disease and the growth of home care programs, it is inevitable that a considerable part of the burden of nursing care in the home, as well as in the hospital, will have to be carried by the trained practical nurse.

\section{The Questions}

In 1952, Montefiore Hospital approached the New York Foundation with a request that it support a 2-year research program designed to answer the following questions:
Without major changes in the length of the curriculum, what are the functions and services which the practical nurse is best prepared to carry out for the sick person in the home? What is the role of the practical nurse in the home on her own; as a member of an organized home care team; or as a member of a visiting nurse service? How much of the training year should be devoted to training in the home? What should be the nature of the training in the home? In addition to training in the home, what changes are desirable in the basic curriculum of practical nurse training which will enable her to do the best job in the care of the sick at home? What is the cost of such a program?

One of the conditions making our situation particularly suitable for this practical nurse demonstration was the close and vital relationship that had been built up in the preceding 5 years between the Montefiore department of home care and the Visiting Nurse Service of New York, the agency under contract for service to Montefiore home care patients (12). A VNS supervisor has also acted as nursing consultant to the program.

With an extensive experience in chronic disease, with a home care program carrying an average census of about 85 patients, with a wellestablished school of practical nursing, with a close tie to the Visiting Nurse Service, and, above all, with the philosophy of the team approach to the care of the chronically sick, the Montefiore Hospital division of social medicine was chosen for this project.

\section{Program Description}

The study was scheduled for October 1, 1952, to October 1, 1954. A full-time supervisor was employed for student orientation, teaching, and general administration of the study. And a contractual agreement was drawn up to cover the care of patients under the joint service of the hospital and the Visiting Nurse Service of New York.

During the 2-year period, 159 students in the Montefiore School of Practical Nursing received a 3-week period of training in the home of patients after basic work in medical and surgical nursing. The average number of stu- 
Table 1. Average student day ${ }^{1}$ in home training project

\begin{tabular}{|c|c|c|}
\hline Activity & Percent & Hours \\
\hline Total_-- & 100 & 8 \\
\hline $\begin{array}{l}\text { Time spent with patient } \\
\text { Travel } \\
\text { Clinical instruction } \\
\text { Home care conference and seminar } \\
\text { Formal class } \\
\text { Recording }\end{array}$ & $\begin{array}{r}37 \\
25 \\
12 \\
6 \\
10 \\
10\end{array}$ & $\begin{array}{l}3 \\
2\end{array}$ \\
\hline
\end{tabular}

1 Does not include lunch.

dents in the program at any given time was six.

A typical period will be of value in presenting some of the activities in the home. During the 6 months, January 1 to June 25, 1954, there were 8 training classes consisting of a total of 35 students who each received a 3-week course in home care. Table 1 shows the average student day during home training and table 2, the activities during the period.

The transition between work in the hospital wards in which a student practical nurse was assigned to limited responsibility for a specific patient to the increased responsibility for a patient in his home presented an educational challenge.

An orientation course of several hours was given to each student on her first day and was continued for as many successive days as needed. This course included statements explaining the philosophy of the home care department, its team approach, and its many patient care func-

Table 2. Visits to patients, nursing hours, and services of 35 students, Jan. 1 to June 25, 1954

\begin{tabular}{|c|c|}
\hline Item & Number \\
\hline $\begin{array}{l}\text { Visits to patients } \\
\text { Total hours } \\
\text { Services performed for patients } \\
\text { General care } \\
\text { Treatments (including physical therapy } \\
\text { and occupational therapy) } \\
\text { Medications } \\
\text { Food and nutrition } \\
\text { Homemaking } \\
\text { Recording } \\
\text { Assisting doctor. } \\
\text { Conferences. } \\
\text { Miscellaneous (including diversion and } \\
\text { encouragement of patient) }\end{array}$ & $\begin{array}{r}724 \\
1,025 \\
10,137 \\
3,767 \\
1,189 \\
273 \\
601 \\
359 \\
1,522 \\
24 \\
853 \\
1,549\end{array}$ \\
\hline
\end{tabular}

tions. The aims and services of the Visiting Nurse Service of New York, as well as the cooperative agreement between the pilot study program and the Visiting Nurse Service, were discussed. Presented in detail were the specific responsibilities of the student to the patient as well as her relationship to the supervisor and to the physician. Modified procedures, such as home methods for sterilizing instruments and thermometers, were demonstrated. Approach to the patient, entry into the home, and attitude and concern for environmental deficiencies were explained. Finally, the individual patient, his physical ailments, and his emotional and social needs were discussed preparatory to the student's initial visit.

Throughout the experience, the student participated in, and contributed to, home care team conferences. Introductory visits to the patient were made jointly by the student and the visiting nurse. At this time, the student could observe the visiting nurse's approach to the patient and her procedures. This made subsequent contacts between the student and the patient more satisfactory. Followup visits were under the guidance of the pilot study supervisor until the student exhibited mastery of a given activity. Students also visited patients with home care physicians, occupational therapists, and physiotherapists, and observed a variety of advanced procedures ranging from thoracentesis to massage and exercise. They observed the staff's interchange of information, which had as its objective improved service to the patient and the family. In the home, students performed a variety of nursing procedures as well as essential homemaking activities.

\section{The Answers}

What is the role of the practical nurse in the home?

The practical nurse demonstrated during this study that she was competent and efficient in a patient's home. She was capable of performing a variety of nursing procedures ranging from a simple bath to sterile dressings, care of tracheotomy patients, administration of oxygen, and preparation of food for patients on regular and special diets. She was able to make necessary and frequently complex adjustments 
of basic skills to meet individual needs in the home.

The practical nurse student, through her training in the home and family setting, developed appreciation of the patient as an individual and of the importance of family relationships in the care of the sick. Each succeeding visit increased her insight and her sensitivity to the emotional stresses and medical, nursing, and socioeconomic problems of her patient.

In a teamwork setting, the student learned the role of the physician and social worker and developed a clear understanding of her own function not only as a practical nurse, but also as a participant in the team. Personal contact between staff members and the practical nurse student fostered mutual respect and understanding. As a member of the Visiting Nurse Service team, she proved her value in effectively relieving the professional nurse of certain routine bedside nursing duties in a manner that was highly acceptable to the patient.

It is, however, important to remember that a 1-year period of training, no matter how excellent, is not designed to give the practical nurse opportunity to learn the many nursing procedures that the professional nurse studies in 3 years.

The advice of Marian G. Randall, executive director of the Visiting Nurse Service of New York, is pertinent: "Continue the excellent plan of teaching patient-centered nursing but give the student the added security of teaching her what she should not do in the home on her own, and of teaching her the signs and symptoms which indicate when she should ask for help and supervision. In the hospital there is always someone near, but in the home the nurse is without professional assistance and there is need to recognize the difference."

Preferably, the practical nurse after her year of training should work within the framework of an agency, such as a visiting nurse service, so that under supervision she may gradually assume greater responsibility in the home.

The Visiting Nurse Service of New York, for instance, employed three of the practical nurse graduates who had received home training, waiving on a trial basis the prerequisite of 1 year of graduate experience. After the VNS supervisor became convinced of their capacity, the practical nurse graduates administered intramuscular injections to selected patients in addition to other duties.

How much of the training year should be devoted to training in the home?

At the outset and on a trial basis, we allocated 3 weeks of the curriculum for the home nursing experience. The first week was devoted largely to student orientation to the program. The program as a whole was discussed, case load assigned, travel directions given, patient care given, patients' case histories studied, and diagnostic signs and symptoms discussed. It was during this first week, too, that the student made, with the visiting nurse, an introductory visit to each of her patients.

The second and third weeks were devoted to assigned case loads under fairly constant supervision of the program supervisor. During this period the various problems that arose were discussed, case studies were written, and examinations given and corrected.

As we gained experience, the faculty concluded that despite a tight curriculum a home training program extended to 4 weeks would provide a broader learning experience. The student could be given more opportunity for independent practice, with supervision as required, and a longer period in which to develop initiative, resourcefulness, and judgment. The supervisor would have more time to evaluate the student's strengths and needs.

\section{What is the nature of the training in the home?}

Observations. The student practical nurse observed the visiting nurse giving care, which included subcutaneous injections and dressings. This was followed by the supervisor's discussion of principles involved in giving care.

Discussion and demonstration. The supervisor demonstrated modifications of procedures such as boiling instruments and cleaning thermometers. She then had the student demonstrate her grasp of these techniques. The visiting nurse shared with the practical nurse student some of the ingenious methods devised over the years which enabled her to work effectively in the home, such as: $(a)$ care of equipment; $(b)$ 
improvised equipment, for example, bed rest and tray made out of cartons; slippers and wastebags made out of newspapers; paper padding in lieu of rubber sheeting.

Formal class teaching. Reading was assigned to students. Class discussion was held on specific illnesses and their signs, symptoms, and medication, all correlated to particular patients. Examinations were given, corrected, and reviewed with the students on an individual as well as a group basis.

Each student was assigned a particular pa tient for whom a written patient-care study was required. These patient-care studies were discussed and evaluated.

Conferences and seminars. The student attended the weekly home care conferences where patients were discussed. The students were free to ask questions. Frequently, a student's patient-care study was used as the basis for discussion at such a conference.

A 2-hour conference was held with each group of students and the occupational therapist. Here, the purpose of occupational therapy and patient suitability for occupational therapy were discussed. In turn, the students frequently called to the attention of the occupational therapist patients who seemed in need of such therapy.

At an orientation conference with the social worker, the students received further insight into understanding the patient as a person and a family member.

Scheduled informal conferences were held by the physical therapist with the students following home visits.

Homemaking duties. Homemaking duties, generally, were minimal. The student was primarily responsible for cleaning the bedside unit.

Since diet and preparation of food are included in the curriculum, the student was familiar with various types of diet, such as bland and salt-free. The program supervisor discussed in detail with each student the dietary requirements of her patients. She stressed the help the nurse could give the patient in understanding and continuing a diet which, while therapeutic, was sometimes quite unpleasant. Whenever necessary, the student prepared and served a patient's food and did other minor household chores. It is interesting and significant that the practical nurse student was unenthusiastic about duties which were specifically homemaking.

\section{What are the necessary curriculum changes?}

The home care experience has resulted in a major reorientation of our curriculum. Not only has it improved the training of practical nurses so that they can function adequately in the home, but it also has sharpened our understanding of the kind of curriculum we require to train a practical nurse to function better in all responsibilities. Heretofore, the curriculum had been focused on mastery of subject matter and nursing procedures as isolated factual material. Even before the pilot study, the need for a patient-centered curriculum had begun to be apparent. In the pilot study, it became quite clear the student was having difficulty in integrating her learning and adapting it to each patient.

The first change was in the content and technique of presenting the more than 70 hours of "conditions of illness." Instead of teaching the major disease entities, the focus was shifted toward the patient with a disease in need of nursing care. All pertinent information relating to the disease-its etiology, symptoms, and treatment, including drugs and diet-was reviewed in the light of its contribution to effective nursing care. The patient's emotional needs and the devastating social effect of long-term illness also were integrated into the teaching program. Advanced nursing procedures, such as thoracentesis, paracentesis, and lumbar puncture, have been included in the conditions of illness course within their appropriate context, rather than presenting them as part of the nursing arts course. Ward conferences, including allied health personnel, revolving around a student's nursing plan for a specific patient have been helpful in training the patient-oriented nurse.

This orientation of the student nurse to the patient may seem so natural and right as to raise the question why it was not done before. Of course, in some measure it always has been done. The problem faced in nursing education parallels that of medical education. The focus of our teaching is so sharply directed toward 
the multiplicity of facts and techniques our students must learn that we tend to forget the primary purpose of nursing education, which is care of the patient. It has been said that the technician has become both so skilled and so narrow that he knows everything about his job but its purpose. It is imperative that the attention of the student nurse be directed as positively to the entire patient as to any group of specific skills. Seeing patients as people and within a family setting is one of the best ways of accomplishing this purpose.

The second deficiency, that of lack of adequate information in the biological areas, has been remedied by another shift in the curriculum. This involved reducing the number of hours allocated to the domestic arts and the hygiene courses and increasing the allocation of hours spent on body structure and function and drugs and solutions.

Our concern with the curriculum is not ended, and it is expected that many more revisions will be made.

\section{Cost of Program}

The cost of the 2-year demonstration of home training for student practical nurses was $\$ 16$,293. A breakdown of the expenditures follows:

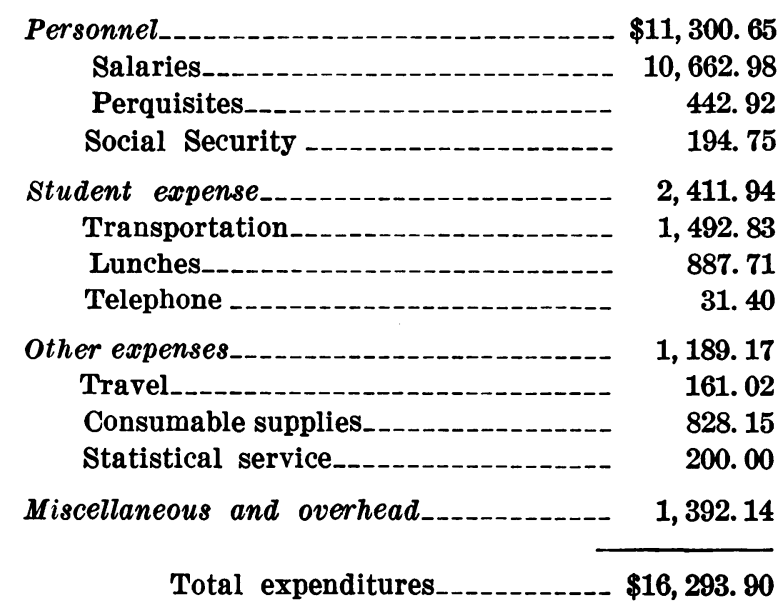

While it cost about $\$ 8,000$ a year to conduct this project on an experimental basis, it is likely that, as a routine part of a school for practical nursing, the same program could be conducted for no more than $\$ 7,000$ a year. This is encouraging since it seems quite obvious that the additional cost of including home care in the curricu- lum will be within the means of most schools. It must be recognized, however, that one of the reasons for the relative inexpensiveness of this additional teaching activity was the presence of a well-organized home care program and a well-organized and cooperative visiting nurse service.

\section{Conclusions}

1. The practical nurse, with proper preparation during her training, can contribute effectively to the growing responsibility for care of patients in the home.

2. The practical nurse, with proper delineation of responsibilities, can supplement and complement the professional nurse.

3. To insure that the practical nurse is prepared for what will inevitably be her responsibility for care in the home (as well as in the hospital), the curriculum for her student training should be primarily patient-oriented. We feel this should include a 4-week period of training in the home, preferably within the framework of a well-organized home care program.

4. The sensitivity, compassion, and understanding, which are the hallmarks of the superior nurse, are not the result of training alone. In many instances, a practical nurse, properly prepared, can bring these attributes to the patient in the home or in the hospital, particularly if she is accepted as a member of the team along with the doctor, the social worker, and the professional nurse.

5. It is not difficult to insert within the curriculum the time necessary for home care, and the budgetary implications are not of such great moment as to make this financially impracticable, particularly if there is an organized program of home care and an effective and cooperating visiting nurse service. Continued experience in training practical nurses in the home and for the home should, and undoubtedly will, lead to further curriculum changes.

6. A program that brings the nursing department of a hospital and the staff of the school of practical nursing into the home has a very beneficial effect upon the attitudes and understanding of the top professional personnel. It is extremely difficult for professional workers to think about patients as whole people 
in society when they are only seen in the narrow setting of an institution. Bringing the staff of the nursing school in close contact with patients, in their natural settings as members of the family in the home, cannot but favorably influence the training of the nurses in the same manner as this device is now being used to favorably influence the training of physicians (13).

NoTE: The Montefiore Hospital demonstration project, supported by a grant from the New York Foundation, is one of several programs sponsored by the National Association for Practical Nurse Education to determine the value of home care training in the practical nurse curriculum. A composite report including the experience of all the programs sponsored by the NAPNE will be published shortly.

\section{REFERENCES}

(1) Cherkasky, M.: Long-term illness. A changing scene. M. Clin. North America. New York No., May 1953, pp. 631-642.

(2) Cherkasky, M.: Montefiore Hospital home care program. Am. J. Pub. Health 39: 163-166, February 1949.

(3) Bluestone, E. M.: Home care. An extramural hospital function. Survey Midmonthly 84: 99-101, April 1948.
(4) Rossman, I.: Treatment of cancer on a home care program. J. A. M. A. 156: 827-830, Oct. 30, 1954.

(5) Jensen, F., Weiskotten, H. G., and Thomas, M. A. : Medical care of the discharged hospital patient. New York, N. Y., Commonwealth Fund, 1944.

(6) Shindell, S.: Preliminary report on Gallinger home study. Am. J. Pub. Health 43: 577-583, May 1953.

(y) Kogel, M. D.: Some aspects of the home care program conducted by the New York City Department of Hospitals. Am. J. Pub. Health 43: 584-588, May 1953.

(8) Bakst, H. J.: Domiciliary medical care and the voluntary teaching hospital. Am. J. Pub. Health 43 : 589-595, May 1953.

(9) Holmes, E. M., Nelson, K., and Harper, O. L., Jr.: Richmond home medical care program. Am. J. Pub. Health 43 : 596-602, May 1953.

(10) American Nurses Association: Facts about nursing. A statistical summary. New York, 1954.

(11) Arestad, F. H., and McGovern, M. A. : Hospital service in the United States. Thirty-third annual presentation of hospital data by the Council on Medical Education and Hospitals of the American Medical Association. J. A. M. A. 155 : 255-278, May 15, 1954. Also Reprint with Supplement.

(12) Randall, M. G.: Community home care program. Am. J. Nursing 49: 651-653, October 1949.

(13) Extramural facilities in medical education. A symposium. J. Med. Educ. 28: 9-53, July 1953.

\section{Joint Services Sanitary Engineer Training Courses}

The first joint training courses for reserve sanitary engineer officers of the commissioned services-Army, Navy, Air Force, and Public Health Service-were held in June 1956 at the Robert A. Taft Sanitary Engineering Center of the Public Health Service in Cincinnati.

Developed jointly by the Department of Defense and Department of Health, Education, and Welfare, in collaboration with the National Research Council, these courses are especially designed for reserve engineer officers normally on inactive status. The courses will bring them up to date on professional developments in sanitary engineering and will provide information on sanitary engineering emergency operations applicable to situations in natural disasters and in military and civil defense emergencies. 